\title{
HUMAN FACTORS GUIDANCE FOR CONTROL ROOM EVALUATION
}

John O'Hara, William Brown, William Stubler, and James Higgins

Brookhaven National Laboratory Upton, New York
Jerry Wachtel and

J.J. Persensky

U.S. Nuclear Regulatory Commission Washington, D.C. 


\begin{abstract}
The Human-System Interface Design Review Guideline (NUREG-0700, Revision 1) was developed by the U.S. Nuclear Regulatory Commission (NRC) to provide human factors guidance as a basis for the review of advanced human-system interface technologies. The guidance consists of three components: design review procedures, human factors engineering guidelines, and a software application to provide design review support called the "Design Review Guideline." Since it was published in June 1996, Rev. 1 to NUREG-0700 has been used success-fully by NRC staff, contractors and nuclear industry organizations, as well as by interested organizations outside the nuclear industry. The NRC has committed to the periodic update and improvement of the guidance to ensure that it remains a state-of-the-art design evaluation tool in the face of emerging and rapidly changing technology. This paper addresses the current research to update of NUREG-0700 based on the substantial work that has taken place since the publication of Revision 1.
\end{abstract}




\title{
HUMAN FACTORS GUIDANCE FOR CONTROL ROOM EVALUATION
}

\author{
John O'Hara, William Brown, \\ William Stubler, and James Higgins \\ Brookhaven National Laboratory \\ Upton, New York
}

\author{
Jerry Wachtel and \\ J.J. Persensky \\ U.S. Nuclear Regulatory Commission \\ Washington, D.C
}

\begin{abstract}
The Human-System Interface Design Review Guideline (NUREG-0700, Revision 1) was developed by the U.S. Nuclear Regulatory Commission (NRC) to provide human factors guidance as a basis for the review of advanced human-system interface technologies. The guidance consists of three components: design review procedures, human factors engineering guidelines, and a software application to provide design review support called the "Design Review Guideline." Since it was published in June 1996, Rev. 1 to NUREG-0700 has been used successfully by NRC staff, contractors and nuclear industry organizations, as well as by interested organizations outside the nuclear industry. The NRC has committed to the periodic update and improvement of the guidance to ensure that it remains a state-of-the-art design evaluation tool in the face of emerging and rapidly changing technology. This paper addresses the current research to update of NUREG-0700 based on the substantial work that has taken place since the publication of Revision 1.
\end{abstract}

\section{BACKGROUND}

Nuclear power plant (NPP) personnel play a vital role in the productive, efficient, and safe generation of electric power. Operators monitor and control plant systems and components to ensure their proper operation. Test and maintenance personnel help ensure that plant equipment is functioning properly and restore components when malfunctions occur. Personnel interact with the plant's systems and components through the human-system interfaces. The human-system interface (HSI) may be defined as the technology, including alarms, displays, procedures, support systems, and controls, through which personnel interact with plant systems to perform their functions and tasks. The HSI is made up of hardware and software components and is characterized in terms of its physical and functional characteristics. Personnel use of the HSI is influenced directily by (1) the organization of HSI components into workstations (e.g., consoles and panels); (2) the arrangement of workstations and supporting equipment into workplaces such as a main control room, remote shuituowin station, local control station, technical support center, and emergency operations facility; and (3) the environmental conditions in which the HSIs are used including radiation, temperature, humidity, ventilation, illumination, and noise.

The importance of HSI design to human performance, and both reliable and safe plant operation, is widely acknowledged. In the early $1980 \mathrm{~s}$, the nuclear industry initiated programs that led to design improvements in conventional HSIs, i.e., HSIs containing analog and primarily hardwired controls (e.g., switches, knobs, and handles) and displays (e.g., gauges, linear scales, and indicator lights). More recently, advanced HSI technology is being integrated into plants as part of modifications to control rooms, remote shutdown facilities, and local panels. The term "advanced" is used in this document to refer to HSI technologies that are largely computer-based. As advanced HSI technologies are integrated into control rooms based on conventional technology, hybrid HSIs are created.

The potential benefits of advanced technology are compelling. New digital systems often provide the opportunity to give personnel information not available from conventional systems. Improved instrumentation and signal validation techniques can help ensure that the information is more accurate, precise, and reliable. In addition, data processing techniques and the flexibility of computer-based information presentation offer designers the ability to present information in ways that are much better suited to personnel tasks and information processing needs. However, if poorly designed and implemented, this technology can negatively impact human performance, create human errors, and reduce human reliability (Woods et al., 1994).

In the U.S., the NRC reviews aspects of HFE in NPPs to ensure that personnel performance and reliability are appropriately supported. The primary method for reviewing the HSI aspects of NPPs is the Human-System Interface Design Review Guideline, NUREG-0700, Rev. 1 (O'Hara et al., 1996). It consists of HFE guidelines, design review procedures, and a software-based, review-support tool called the "Design Review Guideline" (DRG). Since it was published in June 1996, NUREG-0700 has been used successfully by NRC staff, contractors, and nuclear industry organizations, as well as by interested organizations outside the nuclear industry. To ensure that it remains a state-of-the-art design evaluation tool in the face of emerging and rapidly changing technology, the NRC has committed to the periodic update and improvement to the guidance.

Consistent with that objective, the NRC has continued its research program to develop validated HFE guidelines for the review of important new HSI technologies that are likely to be 
used in future new or upgraded control rooms. The topics selected for research and guidance development included: (1) advanced alarm system design, (2) information systems, (3) computer-based procedure systems, (4) soft controls, (5) interface management and navigation, (6) digital system maintenance, and (7) design process and implementation considerations.

\section{GUIDANCE DEVELOPMENT METHODOLOGY}

Woods et al. (1992) observed that the value of guidelines "...lies in the degree to which the guidance can be said to constitute a useful synthesis of the state of knowledge in the field, and in the degree to which it assists in detecting and correcting flaws in the design of human-machine systems." When guidelines accomplish this objective they help assure that an HSI accommodates human physiological and cognitive capabilities. When the effort to update NUREG-0700 began, a methodology was established for guidance development that would provide such a useful synthesis of knowledge. The method development was guided by the objective to establish a process that (1) will result in valid, technically defensible, HFE guidance, (2) can be applied to any aspect of HSI technology for which guidance is needed, and (3) optimally uses available resources, i.e., is cost effective.

The method places a high priority on establishing the validity of the guidelines. Validity is defined along two dimensions: internal and external. Internal validity is the degree to which the individual guidelines are linked to a clear, wellfounded, and traceable technical basis. The technical basis is the information upon which the guideline is established and justified. The technical bases vary for individual HFE guidelines. Some guidelines may be based on technical conclusions from an analysis of empirical research, some on a consensus of existing standards, while others are based on engineering judgement that a guideline represents sound practices based on the information reviewed. Maintaining an audit trail from each guideline to its technical basis serves several purposes enabling: (1) the technical merit of the guideline to be evaluated by others; (2) a more informed application of the guideline since its basis is available to users; and (3) deviations or exceptions to the guideline to be evaluated.

External validity is the degree to which the guidelines are supported by an independent peer review. Peer review is a good method of screening guidelines for conformance to generally accepted HFE practices and to industry-specific considerations, i.e., for ensuring that the guidelines are appropriate based on practical operational experience with the use of HSIs in actual systems.

For individual guidelines, these forms of validity can be inherited from the source documents that form their technical basis. For example, many HFE standards and guidance documents were developed with good internal and external validity. However, when validity is not inherited from the source documents forming its technical basis, it must be established as part of the guidance development process. Our guidance development methodology was established to pro- vide internal validity based on a documented technical basis and external validity based on the test, evaluation, and peer review of the guidance.

The methodology is divided into the following steps (discussed in greater detail below): Characterization of the HSI; Development of the Technical Basis; Development of HFE Guidelines; Identification of Issues; Test, Evaluation, and Peer/Industry Review of Guidance; and Final Guidance Publication.

\section{Characterization of the HSI}

The first step in developing guidance for an HSI topic, such as computer-based procedures, is a needs analysis, i.e., the identification of the areas for which guidance is needed. To accomplish this, we review existing systems and identify the characteristics and functions along which the HSI topic can be defined. The characterization is important because it provides a structure for developing and organizing the guidance.

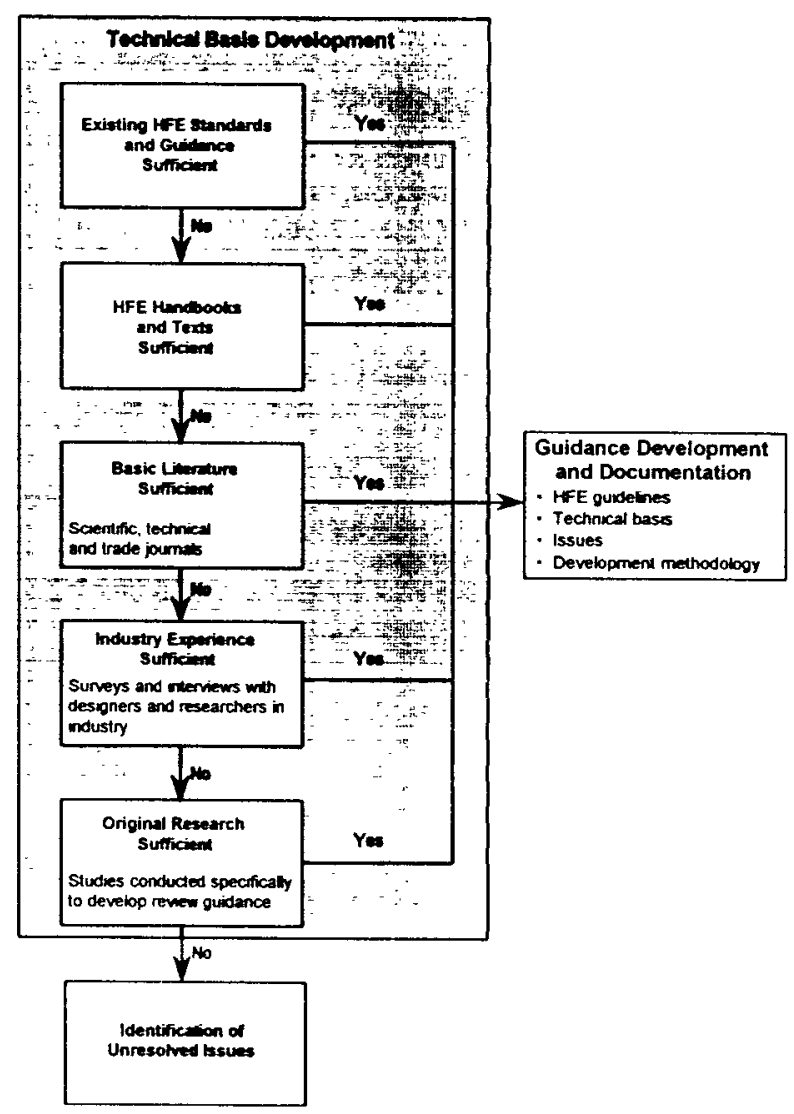

Figure 1. Process for developing the technical basis for guidance and issues

\section{Development of the Technical Basis}

Before guidelines can be developed, the technical information on which guidance will be based must be established. Figure 1 illustrates the use of several sources of information for guidance development, in order of preference. As one proceeds down the flow chart, the information changes in three ways. First, at the top of the flow chart, the source informa- 
tion is already in HFE guidance form. Toward the bottom, the information is in the form of results of individual research studies that must be synthesized and HFE guidelines abstracted. Second, the information at the top already possesses a degree of validity (as discussed above), while towards the bottom the validity of the guidance must be completely established during guidance development. Third, the use of the information for guidance development becomes more costly toward the bottom of the flow chart. Thus, the preference is to use information sources higher in the chart.

We first consider existing HFE standards and guidance documents. In the development of these documents, the authors considered the available research and operational experience, and using their knowledge and expertise, developed HFE guidelines. In addition, they have usually been peer reviewed. Thus, the documents have internal validity, external validity, or both. Further, since the information is already in guideline form, it is generally easier to use. Thus, the documents add tremendous value to individual research reports.

While such documents provide a technically valuable starting place, there may be many aspects of an HSI topic that extend beyond the technology and human performance considerations addressed by these documents. Thus additional sources of information are utilized. We next seek documents providing good syntheses of existing literature, such as handbooks and texts. These documents are valuable in that they generally review research and operational literature and are design oriented. However, the information is usually not expressed in guidance form. Guidance needs to be developed from these documents, but the establishment of technical basis is usually expedited by the information reviewed.

For HSIs reflecting new technology, frequently the sources discussed above are not sufficient to support guidance development. Then, basic literature is reviewed. This literature consists mainly of papers from research journals and technical conferences. Basic literature provides a theoretical basis for understanding human performance concerns related to complex human-machine systems. It also provides general theory for human-machine interaction relevant to user interface design, human error, and usability. Empirical studies of human-machine interaction reported in the literature address a broad range of technologies and user tasks. However, greater effort is needed to develop such information into design guidance. Engineering judgement is required to consider the applicability of these empirical studies to NPP operations. This is because individual experiments tend to have unique constraints that may limit their generalizability (such as their unique participants, types of tasks performed, and types of equipment used). For example, laboratory experiments often do not involve tasks of the complexity of NPP operations, and most experiments do not examine tasks under the same performance shaping factors (such as rotating shifts, stress, and fatigue) that exist in a work environment. While information from research is a valuable part of developing guidance, it cannot be blindly adopted. Thus, the results must be interpreted in the context of real-world tasks and systems, which involves judgement based on professional and operational experience.

Industry experience includes reports and surveys of plant personnel and designers, as well as incident reports that provide information relevant to the HSI topic for which guidance is being prepared. Operational experience can also be obtained from interviews, knowledge-elicitation sessions, and walkthrough exercises using the actual HSI or a high-fidelity training simulator. Industry practices include design approaches that have evolved through experience. They are incorporated into the technical bases as practical examples of the HSI design strategies. This information can be more difficult and costly to obtain than basic literature and may be less reliable. However, it can be more specifically relevant to the NPP domain than basic literature. Like using basic literature, the information needs to be synthesized and guidance developed.

Finally, if the published literature is insufficient, original research may be performed. Original research has the advantage of providing focus on the specific issues that need to be addressed in guidance development. However, because of the time and resources required to conduct original research, it is only used when important information is needed that cannot be obtained through other means.

\section{Development of HFE Guidelines}

Once the technical information is assembled, a set of guidelines is developed from the source materials. The guidelines are organized in a standard format. A database is used to link guidelines with their technical basis and to track changes and modifications that are made as a result of the review and feedback process.

\section{Identification of Issues}

Where there is insufficient information to provide a technical basis from which to develop valid design guidance, an issue is defined. From a research standpoint, issues reflect topics that will require additional investigation to resolve. From a design and evaluation standpoint, issues reflect aspects of design that will have to be addressed on a case-by-case basis, e.g., using design-specific tests and evaluations.

\section{Test, Evaluation, and Peer/Industry Review of Guidance}

If warranted, tests and evaluations can be performed that enable the guidance to be modified and improved prior to its broader peer and industry review. For example, tests can be performed by having representative users apply the guidance for its intended purpose. Peers knowledgeable with the subject matter of the guidance then review it. These reviews include evaluations of the HSI topic characterizations and the guidance. It is evaluated with respect to its scope, comprehensiveness, technical content, technical basis (adequacy of its internal validity), and usability (i.e., presentation, functionality, procedures, tools, and user interface). Comments from the peer reviews are used to revise the guidance. 
The draft guidance may then submitted for review to a broad range of organizations and the general public. Their comments are obtained and resolved, including the identification of any necessary modifications to the guidance.

\section{Final Guidance Publication}

The final guidance will be integrated into NUREG-0700 and the technical basis, development methodology, and unresolved research issues will be documented in a series of technical reports addressing each topic.

\section{CONCLUSIONS}

Technical reports will be published in the year 2000 addressing (1) advanced alarm system design; (2) information systems, (3) computer-based procedure systems, (4) soft controls, (5) interface management and navigation, (6) digital system maintenance, and (7) design process and implementation considerations. The update of NUREG-0700 will follow shortly thereafter. The guidance development process and update of NUREG-0700 to address these important HSI topics will ensure that the guidance remains a state-of-the-art design evaluation tool.

\section{ACKNOWLEDGEMENTS}

The U.S. Nuclear Regulatory Commission is sponsoring this research. The views presented in this paper represent those of the authors alone, and not necessarily those of the NRC.

\section{REFERENCES}

O'Hara, J., Brown, W.. Stubler, W., Wachtel, J., and Persensky, J. (1996). Human-system interface design review guideline (NUREG-0700, Rev. 1). Washington, DC: U.S. Nuclear Regulatory Commission.

Woods, D., Johannesen, L., Cook, R., and Sarter, N. (1994). Behind human error: Cognitive systems, computers, and hindsight (CSERIAC SOAR 94-01). Wright Patterson Air Force Base, Ohio: Crew Systems Ergonomics Information Analysis Center.

Woods, D., Johannesen, L., and Potter, S. (1992). The sophistry of guidelines: Revisiting recipes for color use in human-computer interaction. In Proceedings of the Human Factors Society 36th Annual Meeting, Santa Monica, CA: Human Factors Society. 